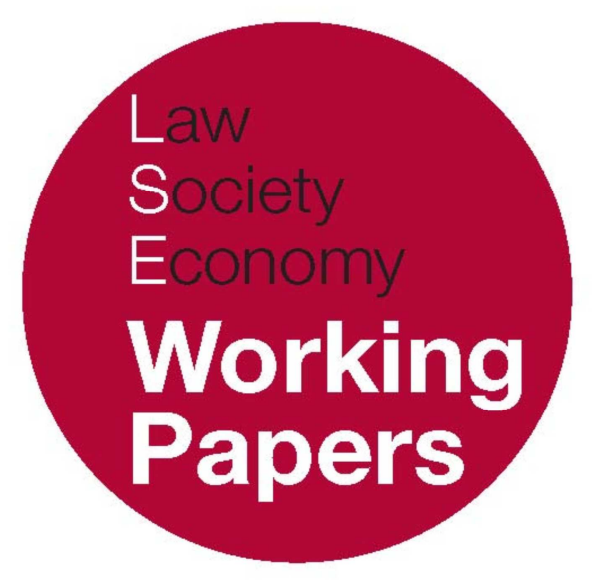

\title{
Proportionality and Rights Inflation
}

\author{
Kai Möller
}

\author{
LSE Law, Society and Economy Working Papers 17/2013 \\ London School of Economics and Political Science \\ Law Department
}

\begin{abstract}
This paper can be downloaded without charge from LSE Law, Society and Economy Working Papers at: www.lse.ac.uk/collections/law/wps/wps.htm and the Social Sciences Research Network electronic library at: http://ssrn.com/abstract=2272979.

(C) Kai Möller. Users may download and/or print one copy to facilitate their private study or for non-commercial research. Users may not engage in further distribution of this material or use it for any profit-making activities or any other form of commercial gain.
\end{abstract}




\title{
Proportionality and Rights Inflation
}

\author{
Kai Möller
}

\begin{abstract}
Proportionality is the most important principle of constitutional rights law around the world, but our theoretical grasp of both the principle itself and the conception of rights of which it is the crucial part is still emerging. The goal of this chapter is to contribute to the scholarly discussion on proportionality by exposing and exploring an important link between proportionality and rights inflation, that is, the phenomenon that increasingly relatively trivial interests are protected as rights. My claim is that proportionality is not only compatible with rights inflation, but that it necessitates it: under a theory of rights that endorses proportionality, there is no coherent way to avoid the conclusion that all autonomy interests should be protected as rights, and this includes interests in engaging in trivial and even immoral activities. Although this intuitively implausible result may strengthen some in their doubts about or rejection of proportionality, this chapter will proceed by showing that, while my argument, if correct, necessitates the revision of some widely held views about the nature and justification of human and constitutional rights, there is nothing incoherent or unattractive about such a view. On the contrary, rights inflation and proportionality are part and parcel of an attractive conception of constitutional rights.
\end{abstract}

\footnotetext{
* Department of Law, London School of Economics and Political Science. Email: k.moller@1se.ac.uk. I am grateful to Grégoire Webber and Grant Huscroft for their helpful comments on earlier drafts. This paper will be published as a chapter in G Huscroft, BW Miller, and G Webber (eds) Proportionality and the Rule of Law: Rights, Reasoning, Justification, forthcoming. All references in this paper to 'this volume' refer to this forthcoming book.
} 


\section{INTRODUCTION}

Proportionality is the most important principle of constitutional rights law around the world, but our theoretical grasp of both the principle itself and the conception of rights of which it is the crucial part is still emerging. The goal of this chapter is to contribute to the scholarly discussion on proportionality by exposing and exploring an important link between proportionality and rights inflation, that is, the phenomenon that increasingly relatively trivial interests are protected as rights. My claim is that proportionality is not only compatible with rights inflation, but that it necessitates it: under a theory of rights that endorses proportionality, there is no coherent way to avoid the conclusion that all autonomy interests should be protected as rights, and this includes interests in engaging in trivial and even immoral activities. Although this intuitively implausible result may strengthen some in their doubts about or rejection of proportionality, this chapter will proceed by showing that, while my argument, if correct, necessitates the revision of some widely held views about the nature and justification of human and constitutional rights, there is nothing incoherent or unattractive about such a view. On the contrary, rights inflation and proportionality are part and parcel of an attractive conception of constitutional rights.

\section{THE PRINCIPLE OF PROPORTIONALITY}

Proportionality is a doctrinal tool to establish whether an interference with a prima facie right is justified, and this justification succeeds if the interference is 'proportionate' (or alternatively and probably more precisely, if it is 'not disproportionate'). The test consists of four stages: ${ }^{1}$ first, the interference must serve a legitimate goal; second, it must be suitable for the achievement of that goal (suitability, rational connection); third, there must not be a less restrictive but equally effective alternative (necessity); and fourth and most importantly, the interference must not be disproportionate to the achievement of the goal (balancing, proportionality in the strict sense).

\footnotetext{
1 There exist slightly different versions of the test in different jurisdictions. For the purposes of this chapter, those differences do not matter as long as balancing features as part of the test. The Canadian understanding often tries to avoid explicit reliance on balancing and resolves at the least restrictive means stage issues that, in other jurisdictions, are considered at the balancing stage. Denise Réaume criticises this, arguing that 'this question [the question of which of the values is more important], which has so often been disguised and hidden elsewhere in the steps of the Oakes test, or simply not been addressed, properly belongs at the end of the process, with the other steps serving simply to disqualify bad justificatory arguments and refine the ultimate contest'. See Denise Réaume, 'Limitations on Constitutional Rights: The Logic of Proportionality', (2009) University of Oxford Legal Research Paper Series, Paper No. 26/2009 at 26. Dieter Grimm makes essentially the same point in his 'Proportionality in Canadian and German Constitutional Jurisprudence', (2007) 57 University of Toronto Law Journal 383.
} 
The principle is best understood as providing guidance in the structured resolution of a conflict between a (prima facie) right and another right or a public interest. The legitimate goal stage identifies the conflicting value. The suitability stage determines the extent to which there is a genuine conflict between the two in the sense that one can only be realised at the cost of the other: when a policy which interferes with a right does not contribute to the achievement of the legitimate goal, then there is no conflict between the right and the goal. The necessity stage requires that the conflict be resolved in a way that is as respectful of the right as possible; thus, the less restrictive but equally effective alternative must be chosen. Although the suitability and necessity stages are important for the overall test, in most cases the decisive stage is the balancing stage where the two values are balanced against each other. The challenge that proportionality in general and balancing in particular present to traditional philosophical theories of rights is that they do not recognise any special normative force of rights, for example by regarding them as trumps or side constraints. ${ }^{2}$ Rather, rights operate on the same plane as (conflicting) policy considerations, and it is precisely for this reason that it is appropriate to 'balance' them against conflicting public interests. Robert Alexy's influential theory of rights as principles (which have to be balanced against competing principles) captures this feature of contemporary rights jurisprudence nicely. ${ }^{3}$

\section{CONSTITUTIONAL RIGHTS AND THE TREND TOWARDS RIGHTS INFLATION}

Constitutional rights protect autonomy interests such as a person's interests in life and physical integrity, freedom of expression, private life, or freedom of religion. I refer to these interests as 'autonomy' interests in order to stress that what is protected by constitutional rights is not an entitlement to live one's life in accordance with some objectively valuable way of life, but rather one to live it in accordance with the agent's ('subjective') self-conception: the agent is prima facie entitled to live his life in accordance with his views on who he is and who he would like to be, for the determination of which considerations relating to his personal history and circumstances and his position within his social environment will be crucial. ${ }^{4}$ This understanding of the freedom protected by constitutional rights helps explain the set of traditionally acknowledged rights, such as the right to freedom of religion (religion is often an important part of a person's self-

\footnotetext{
2 On rights as trumps, see inter alia Ronald Dworkin, 'Rights as Trumps' in Jeremy Waldron (ed), Theories of Rights (1984); on rights as side constraints, see Robert Nozick, Anarchy, State, and Utopia (Blackwell, 1974), ch 3.

${ }^{3}$ Robert Alexy, A Theory of Constitutional Rights (Oxford University Press, 2002).

${ }^{4} \mathrm{I}$ develop this point in greater length in my 'Two Conceptions of Positive Liberty: Towards an Autonomy-based Theory of Constitutional Rights', (2009) 29 Oxford Journal of Legal Studies 757 at 772 776.
} 
conception), private life (which is partly about protecting certain important choices, for example relating to sexual relationships and procreation), freedom of expression, and others. ${ }^{5}$ Furthermore, it explains those rights that are not about activities, but about what one might call a person's resources, such as his life, property and personal data: autonomy is not, under the conception endorsed here, primarily about actions; rather it is about being able to live one's life, and the protection of life, property, and personal data is, for different reasons, important for this. ${ }^{6}$

The interests and rights mentioned in the previous paragraph have in common that they are all relatively important for the purpose of living one's life. What about interests in engaging in activities that are of less importance? Especially in Europe, the protection offered by constitutional rights extends to relatively trivial interests. The European Court of Human Rights routinely reads such interests into the right to private life (Article 8 of the European Convention on Human Rights). For example, in the famous Hatton case concerning a policy scheme that permitted night flights at Heathrow airport, thus leading to noise pollution which disturbed the sleep of some of the residents living in the area, the Court discovered as part of Article 8 the right not to be 'directly and seriously affected by noise or other pollution', 7 dismissively dubbed 'the right to sleep well' by George Letsas. ${ }^{8}$ The broad understanding which the Court takes towards the right to private life becomes clear in one of its more recent attempts to circumscribe it:

The Court recalls that the concept of 'private life' is a broad term not susceptible to exhaustive definition. It covers the physical and psychological integrity of a person. It can therefore embrace multiple aspects of the person's physical and social identity. Elements such as, for example, gender identification, name and sexual orientation and sexual life fall within the personal sphere protected by Article 8. Beyond a person's name, his or her private and family life may include other means of personal identification and of linking to a family. Information about the person's health is an important element of private life. The Court furthermore considers that an individual's ethnic identity must be regarded as another such element. Article 8 protects in addition a right to personal development, and the right to establish and develop relationships with other human beings and the outside world. The concept of private life moreover includes elements relating to a person's right to their image. ${ }^{9}$

${ }^{5} \mathrm{Ibid}$ at $776-783$

${ }^{6}$ Ibid.

${ }^{7}$ Hatton v. United Kingdom, (2003) 37 E.H.R.R. 28 at para. 96.

${ }^{8}$ George Letsas, A Theory of Interpretation of the European Convention on Human Rights (Oxford University Press, 2007) at 126.

9 S v. United Kingdom, (2009) 48 E.H.R.R. 50 at para. 66 (references omitted). 
Thus, the Court has considered the storing of fingerprints and DNA samples by the state ${ }^{10}$ and the publication of photographs of a person in her daily life by a magazine ${ }^{11}$ as falling within the scope of 'private life'. Article 8 also protects a right of access to the information relating to a person's birth and her origin. ${ }^{12}$ With regard to sexual autonomy, the Court held not only that consensual homosexual sex was part of 'private life', 13 but also that homosexual sado-masochistic group sex orgies involving considerable violence were included within the scope of Article $8 .{ }^{14}$

Although the European Court of Human Rights has not provided a comprehensive definition of the meaning of 'private life', it requires that the interest in question be part of 'private life', whatever that term exactly means; thus, the Court will not accept any interest as falling within the scope of Article 8. In other words, there is a threshold to be crossed for an interest to become a right. By way of contrast, the German Federal Constitutional Court has explicitly given up any threshold requirement to distinguish a mere interest from a constitutional right. As early as 1957, it held that Article 2(1) of the Basic Law, which protects everyone's right to freely develop his or her personality, is to be interpreted as a right to freedom of action. ${ }^{15}$ The Court provided various doctrinal reasons for this result, its main argument being that an earlier draft of Article 2(1) had read 'Everyone can do as he pleases' (Jeder kann tun und lassen was er will'), and that this version had been dropped only for linguistic reasons. ${ }^{16}$ The Court re-affirmed this ruling in various later decisions; most famously, it declared that Article 2(1) included the right to feed pigeons in a park ${ }^{17}$ and the right to go riding in the woods. ${ }^{18}$

The explanation of this trend towards rights inflation must be found either in the unwillingness or the inability of the courts to identify a threshold that separates important interests which attract the protection of human or constitutional rights from those that are relatively trivial. The following section will examine the issue of the threshold by identifying a link between the appropriate scope of prima facie rights and the principle of proportionality.

\footnotetext{
${ }^{10}$ Ibid at para. 67.

${ }^{11}$ Von Hannover v. Germany, (2005) 40 E.H.R.R. 1 at para. 53.

12 Odievre v. France, (2004) 38 E.H.R.R. 43 at para. 29.

${ }^{13}$ Dudgeon v. United Kingdom, (1982) 4 E.H.R.R. 149 at paras. 40-41.

14 Laskey, Jaggard and Brown v. United Kingdom, (1997) 24 E.H.R.R. 39 at para. 36. The Court left the question open whether the activities in question fell within the scope of Article 8 in their entirety, but proceeded on the assumption that they did.

${ }^{15}$ BVerfGE 6 at 32 (Elfes).

$16 \mathrm{Ibid}$. at 36-37.

${ }^{17}$ BVerfGE 54 at 143 (Pigeon-Feeding).

18 BVerfGE 80 at 137 (Riding in the Woods).
} 


\section{THE RELATIONSHIP BETWEEN PROPORTIONALITY AND RIGHTS INFLATION}

The argument of this section is that there is a connection between proportionality and rights inflation. It is widely accepted that proportionality analysis is compatible with rights inflation: for example, it is perfectly possible to accept, as the German FCC does, a right to feed birds, and then to apply proportionality analysis in order to establish whether an interference with this right is justifiable. My argument in this chapter goes further than this: I claim that proportionality is not only compatible with rights inflation, but that it necessitates it. Proportionality and rights inflation are two sides of the same coin, or two features of the same conception of rights.

\section{THE INEVITABILITY OF RIgHTS INFLATION}

One of the features of proportionality analysis in general and its balancing stage in particular is that rights are not seen as different in structure from mere interests or policy considerations: this is why they can and must be balanced against them, as opposed to being awarded some special normative force (for example, as trumps or side constraints upon action) making them wholly or partly immune to tradeoffs. ${ }^{19}$ This section will demonstrate that if rights do not hold special normative force, then any attempt to limit their scope would be arbitrary; thus, coherence requires that rights inflation be embraced.

What would be wrong with accepting that while rights do not hold special normative force, the scope of rights should be limited to certain important interests? Consider the example of hobbies: collecting stamps, playing tennis, or riding in the woods. Although these hobbies may be reasonably important activities for the people engaging in them, they do not display crucial life decisions such as whether to procreate, whom to choose as a partner, or which profession to take up. Would it not be possible to say that although hobbies have some importance for autonomy, this importance is simply not great enough to attract the protection of constitutional rights? The idea would be to introduce a threshold of importance, and only autonomy interests that reach a certain level of importance would be protected as constitutional rights. If protected, any limitation of those rights would be permissible only if proportionate; in turn, an autonomy interest that did not reach the threshold would not be protected and could therefore be limited unrestrictedly. This model, the threshold model, can be contrasted with the comprehensive model, according to which any autonomy interest, however trivial, is sufficient to attract the protection of constitutional rights.

${ }^{19}$ Fred Schauer argues, to the contrary, that rights are worth more than non-rights protected interests. See 'Proportionality and the Question of Weight', in this volume. 
An autonomy-based conception of constitutional rights must favour the comprehensive model for two reasons. First, under the logic of an autonomybased approach, the relevant question must be whether the interest in question has some, however small, importance: as long as it has some importance, as is certainly the case with the pursuit of hobbies, something would be lost for autonomy if it were not protected at all. This leads to the second point: the threshold model would have to draw a line somewhere, stipulating that anything below that line falls foul of the necessary threshold and is therefore not protected. However, it is hard to see how such a threshold could be set in a non-arbitrary way. Would the interest have to be of reasonable, average, high, or of fundamental importance? What should be the criteria here? The consequence of accepting a threshold at any specific level of importance would be that an interest that is just below the threshold receives no protection whatsoever, whereas an interest which is just above the threshold can only be interfered with in a proportionate manner. This difference in protection cannot be justified if all that separates the two interests is a tiny margin of importance: it is simply incoherent to attach such morally significant consequences to such a small difference in importance. To be sure, we might just draw the line somewhere in a pragmatic way and declare that from now on, only interests that are at least, say, 'very' important are protected. But the defining feature of pragmatic approaches to moral questions is the absence of principle, and we are looking for a principled approach to limit the domain of constitutional rights; therefore, a pragmatic solution is not acceptable.

To the above conclusion, one might object that it is simplistic to assume that the threshold must be set at some level of importance, such as 'reasonable' or 'high' importance. Perhaps the threshold points to a qualitative difference? The most promising attempt in this direction has been made by James Griffin in his book On Human Rights, and his discussion is of particular interest in the present context because Griffin's conception of human rights relies heavily on the value of personal autonomy (albeit under a slightly different terminology). He argues that the threshold can be derived from the idea of personhood:

Human life is different from the life of other animals. We human beings have a conception of ourselves and of our past and future. We reflect and assess. We form pictures of what a good life would be [...] And we try to realise these pictures. This is what we mean by a distinctively buman existence $[\ldots]$ And we value our status as human beings especially highly, often more highly than even our happiness. This status centres on our being agents deliberating, assessing, choosing, and acting to make what we see as a good life for ourselves.

Human rights can then be seen as protections of our human standing or, as I shall put it, our personhood. And one can break down the notion of personhood into clearer components by breaking down the notion of agency. To be an agent, in the fullest sense of which we are capable, one must (first) choose one's own path 
through life - that is, not be dominated or controlled by someone or something else (call it 'autonomy'). [...] [And] (third) others must not forcibly stop one from pursuing what one sees as a worthwhile life (call this 'liberty'). ${ }^{20}$ Griffin tells us more about how demanding the right to liberty is:

[L]iberty applies to the final stage of agency, namely to the pursuit of one's conception of a worthwhile life. By no means everything we aim at matters to that. Therefore, society will accept a person's claim to the protection of liberty only if the claim meets the material constraint that what is at stake is indeed conceivable as mattering to whether or not we function as normative agents. $^{21}$

Griffin's idea is that 'personhood' functions both as the basis of human rights and as a limitation on their scope: only those interests that are important for personhood are protected as human rights. So we might argue that constitutional rights ought to protect only interests that are important for personhood, and that constitutional rights protecting personhood can then only be limited when this limitation is proportionate. In light of the importance of the value of personhood, limitations of rights will normally be disproportionate at least when they are pursued for the protection of values that are not grounded in personhood. On this account, we might endorse proportionality and reject rights inflation.

However, this account does not work. Its failure is that the personhood approach does not offer a coherent way to delineate interests relevant for personhood from other interests. For Griffin, personhood requires autonomy and liberty (in my terminology, personal autonomy): basically, control over one's life. But it requires only that kind of control over one's life that is required by the value of personhood. This leaves open the question of what the test is for determining whether some instance of liberty (autonomy) is required for personhood. My suspicion is that it is simply 'importance'. For example, Griffin explains that 'the domain of liberty is limited to what is major enough to count as part of the pursuit of a worthwhile life'. ${ }^{22}$ At another point, he defends a human right to gay marriage on the ground 'of its centrality to characteristic human conceptions of a worthwhile life'. ${ }^{23}$ Thus, it seems that the threshold of personhood simply refers back to a sliding scale of importance: an interest that is 'major enough' or 'central' will acquire the status of a human right. But such a sliding scale cannot, as explained above, do the moral work. The threshold would have to be between 'not quite major enough' and 'barely major enough' or 'not quite central', and 'barely central'.

${ }^{20}$ James Griffin, On Human Rights (Oxford University Press, 2008) at 32-33 [Griffin, Human Rights]. Griffin's second point, omitted in the quote, is about 'minimum provision' of resources and capabilities that it takes to be an agent.

21 Ibid at 167.

22 Ibid at 234 (emphasis added).

23 Ibid at 163 (emphasis added). 
But then, under Griffin's model, all that separates an interest that is just below from one that is just above the threshold is a small difference in terms of importance or centrality, and this small difference cannot justify the great normative significance that for proponents of threshold models comes with one of them being a simple interest and the other a human right. I believe that this is a general problem of threshold theories that is not limited to Griffin's account. ${ }^{24}$ If that is true, then the only possible conclusion is that the threshold requirement should be dropped and it should be acknowledged that the scope of freedom protected by rights must extend to everything that is in the interest of a person's autonomy.

This conclusion sits well with the practice of constitutional rights law and its trend towards rights inflation; and herein lies a further indicator of its correctness. Someone might object that although such a trend exists, it would still be an overstatement to say that constitutional rights law generally protects all autonomy interests as rights. This is true insofar as the German account of freedom of action as including the rights to go riding in the woods and feed pigeons in the park remains an outlier in constitutional rights law around the world. But it must be acknowledged that once we agree that the point of constitutional rights is to enable people to follow their projects, the inclusion of hobbies loses any flavour of absurdity. In fact, on this understanding, the only difference between the German approach and other, less generous approaches is that the German approach sets the threshold lower, or even sets aside any threshold, whereas other jurisdictions continue to follow a threshold model. But the most likely explanation for this threshold lies not in a morally different conception of rights, but in a simple institutional consideration, namely a sense that constitutional courts should, because of their limited resources, only deal with matters of a certain importance. This presents only a minor variation in the scope of rights adopted in different jurisdictions and leaves intact their moral core as being about protected autonomy interests comprehensively understood.

\section{THE INCLUSION OF 'EVIL ACTIVITIES'}

The question whether both liberty and rights, properly understood, include immoral or even 'evil' 25 activities such as murdering is a recurrent one in political theory. ${ }^{26}$ The dispute is not about whether such activities can be prohibited - of course they can; in fact, taking into account the widely acknowledged doctrine of positive obligations, they usually must be prohibited. Proponents of a wide understanding of rights include murdering at the prima facie stage, but there is no

\footnotetext{
${ }^{24}$ For a similar view, cf. Joseph Raz, 'Human Rights without Foundations', in Samantha Besson and John Tasioulas (eds), The Philosophy of International Law (Oxford University Press, 2010), at 326 [Raz, "Human Rights"].

25 The point of labelling the activities in question somewhat vaguely as 'evil' is to indicate that they are the sorts of activities that, because of their extremely harmful and immoral nature, nobody can possibly have a definite right to engage in.

26 See Isaiah Berlin, 'Two Concepts of Liberty' in Liberty (2002) 166 at 169; Ronald Dworkin, Justice in Robes (Harvard University Press, 2006) at 112.
} 
doubt that there are reasons of sufficient weight (in particular, the rights of the possible victims) in favour of a prohibition, which are to be taken into account at the justification stage. In fact, proportionality seems to be ideally suited to conduct this inquiry: an approach that first acknowledges that there is a right to murder and then, at the justification stage, deals with the permissible limitations of this right addresses all morally relevant considerations and reaches the right conclusion. So what is the problem with a right to murder?

I believe that many will be hesitant about accepting that there is a genuine (autonomy) 'interest' in engaging in immoral or evil activities. One might argue that a person can only have an interest in an activity if that activity carries some value; and that since in the case of murdering there is no such value, no interest in murdering should be acknowledged. Consequently, a prohibition of murder does not engage a person's interests, properly understood, and is therefore not in need of justification.

However, we must be careful not to confuse two distinct issues. It does not follow from the fact that murdering is worthless that we ought to deny the existence of an autonomy interest in murdering. If that logic were correct, then a person could not possibly have interests, protected by rights, in engaging in worthless activities, and that seems wrong. An attractive understanding of the freedom protected by constitutional rights cannot protect only those exercises of freedom which are valuable. Rather, a commitment to personal freedom includes a commitment to moral agency, and this means that it must in principle be left to the agent to decide for himself whether a particular activity is morally valuable. For example, in the old debates about the decriminalisation of homosexual sex, one of the two important arguments was that the question whether homosexual sex is valuable is not the business of the state; rather, it is for each agent to decide this for himself. (The second argument is that there is nothing morally wrong with homosexuality or homosexual sex; but this is an independent point and even if it were not true, homosexual sex should be protected by rights.) But this point can be generalised and it can be concluded that judging the value of an agent's project is not the business of the state. Thus, the question cannot be whether it is objectively the case that murdering (or any other activity) is valuable or not, but the crucial question must be whether the activity is valuable from the perspective of the agent. If it is, then the agent has an autonomy interest in the activity that must be protected by a right.

This does of course not mean that 'anything goes': if someone chooses murdering as his project, he should be punished because he violates the rights of others. But he should not be punished on the ground that he has chosen a worthless project. The same point is captured by Ronald Dworkin's distinction between ethics and morality: ethical questions are about how to live a good life, 
whereas moral questions concern the duties we owe to each other. ${ }^{27}$ The prima facie stage of rights is solely concerned with ethics in the Dworkinian sense: the murderer, as a moral agent, is entitled to decide for himself whether murdering promotes or ruins the value of his life. In a community committed to personal freedom, judging the value of his projects is the agent's responsibility and not that of the state.

Under a proportionality-based approach to rights, there must be a right to engage in 'evil' activities; this can be explained in the following way. There are two possible reasons why the state might want to prohibit such activities. The first is their ethical worthlessness; but as explained above, judging ethical value is not the rightful concern of the state. The second is their immorality. This issue is indeed the concern of the state, but under proportionality, it is addressed at the justification stage, where the rights of others and relevant public interests are considered, and those rights reflect precisely the domain of morality in the Dworkinian sense. Adding a 'morality filter' for 'evil' activities at the prima facie stage would lead to conducting the same inquiry at two different stages of the test and would thus point to incoherence and structural confusion.

\section{IMPLICATIONS FOR A PROPORTIONALITY-BASED THEORY OF RIGHTS}

The conclusion of the previous section may embolden some in their scepticism about proportionality-based judicial review. It is certainly true that, intuitively, many will find the phenomenon of rights inflation troubling and would prefer to see it limited rather than comprehensively embraced; and things seem to get even worse when immoral and "evil" activities are regarded as falling within the scope of rights. My argument in this section will not be that because of those arguably counter-intuitive conclusions, proportionality-based judicial review should be abandoned or modified. On the contrary, I will argue that both proportionality and rights inflation are part of an attractive conception of rights. To grasp its appeal, one must dispense with some traditionally held views about human and constitutional rights.

Why do many perceive rights inflation as a troubling development? Rights inflation calls into question two related and deeply held views about human and constitutional rights: (1) that they protect only interests of a special importance, and (2) that it is this special importance which lends rights their special normative force. Rights inflation denies both premises: rights do not have a special importance, and precisely because of the lack of special importance they do not have special normative force. Proportionality affirms this because proportionality, just like

27 Ronald Dworkin, Is Democracy Possible Here? Principles for a New Political Debate (Princeton University Press, 2006) at 21. 
rights inflation, denies the special normative force of rights, and as shown in the previous section, properly understood, it must also deny their special importance.

Thus, the conception of rights of which rights inflation and proportionality are features challenges some views about rights to which many are strongly committed. Is it possible to preserve a special role for rights while denying that they have special importance and special normative force? I want to propose the following account of the point and purpose of human and constitutional rights. Human rights are commonly referred to as the rights to which a person is entitled simply by virtue of his or her humanity. Most would agree that the best interpretation of this very abstract idea has something to do with personal autonomy (Griffin would say, autonomy and liberty). But it does not follow that we should think about the point of autonomy as being provided with certain goods (in particular, freedoms), such as the freedoms to speak one's mind, choose one's partner, and follow one's religion. Under proportionality-based judicial review, the main entitlement that a human being has simply by virtue of being human and with regard to how she lives her life is being treated with a certain attitude: an attitude that takes her seriously as a person with a life to live, and that will therefore deny her the ability to live her life in a certain way only when there are sufficiently strong reasons for this. Applied to the case of hobbies such as feeding the birds, this means that we should not ask whether the freedom to feed birds is indispensable for making a person a person. Rather, we should ask whether the state treats a person subject to its authority in a way which is in line with that person's status flowing from her humanity when the state prohibits, for example, her participation in the activity of feeding birds; and this will be the case only when there are sufficiently strong reasons supporting the prohibition. Thus, the point of rights is not to single out certain especially important interests for heightened protection. Rather, it is to show a particular form of respect for persons by insisting that each and every state measure which affects a person's ability to live her life according to her self-conception must take her autonomy interests adequately into account.

Rights inflation and proportionality are the two crucial features of a conception of rights that embodies this basic idea. Rights inflation is required because showing the right attitude towards a person requires taking all of his projects seriously, including those of trivial importance and even immoral or 'evil' ones. Proportionality is required because, properly understood, it assesses precisely the question of whether a person's autonomy interests have been adequately taken into account by the policy that interferes with his autonomy. For this to be the case, (1) the policy must pursue a legitimate goal; (2) it must be a suitable means of achieving that goal; (3) there must not exist a less restrictive but equally effective alternative means; and (4) it must not impose a disproportionate burden on the right-holder. Where one of these conditions is not met, the reasons for the 
limitation are not sufficiently strong; where all four conditions are met, they are and the policy is therefore constitutionally legitimate. ${ }^{28}$ This approach makes sense of the powerful idea of 'simply in virtue of being human' without taking the misguided step from that idea to an entitlement to certain especially important freedoms.

Furthermore, this approach helps to rebut an objection that might be raised against a conception of rights that endorses rights inflation, namely that it succumbs to a conceptual confusion by acknowledging the existence of a right without giving an account of its corresponding duties. One might argue that something does not become a right simply by virtue of the fact that it is important for my autonomy. For example, if it is the case that I enjoy feeding birds in my local park, it may follow that I have an autonomy interest in feeding the birds, but it may be an entirely different question of whether I do indeed have a right to feed the birds. Consider Raz's famous account of rights:

Definition: ' $\mathrm{X}$ has a right' if and only if $\mathrm{X}$ can have rights, and, other things being equal, an aspect of X's well-being (his interest) is a sufficient reason for holding some other person(s) to be under a duty.29

This is sometimes taken to mean that all one needs for a right to come into existence is an interest; but this is based on a misunderstanding. Rather, it must be the kind of interest which grounds duties in others. Thus, as Raz explains elsewhere, just because the love of my children is the most important thing to me, it does not follow that I have a right to it. ${ }^{30}$ To get back to the example of feeding birds, just by virtue of the fact that feeding the birds is of some importance to me, it does not follow that I have a right to it unless this interest can be shown to ground a duty of non-interference in the state.

The straightforward solution to this problem lies in the distinction between prima facie rights and definite rights. A definite right to engage in a particular activity indeed grounds a duty of non-interference on the side of the state. The prima facie right, by way of contrast, grounds a different duty: the duty of the state to take the respective autonomy interest adequately into account. For example, the prima facie right to feed birds grounds the state's duty to take the autonomy interest in bird feeding adequately into account in its policy making; and this means that feeding birds can only be regulated or prohibited if there exist sufficiently strong reasons for such interference (for example the prevention of pollution) which are such that they justify the prohibition or regulation in spite of the fact that thereby

\footnotetext{
28 Cf. Mattias Kumm, 'The Idea of Socratic Contestation and the Right to Justification: The Point of Rights-Based Proportionality Review' (2010) 4 Law \& Ethics of Human Rights 141 at 144: '[The proportionality test] provides little more than a check-list of individually necessary and collectively sufficient criteria that need to be met for behaviour by public authorities to be justified in terms of reasons that are appropriate in a liberal democracy. In that sense it provides a structure for the assessment of public reasons.'

${ }^{29}$ Raz, The Morality of Freedom (1986) at 166.

${ }^{30} \mathrm{Raz}$, 'Human Rights', supra note 24 at 325.
} 
the would-be bird feeder is denied the pursuit of this activity. This understanding of rights and their corresponding duties resolves the conceptual puzzle and explains why it is indeed coherent to accept a right to everything that is in the interest of a person's autonomy.

\section{WEBBER'S CRITIQUE}

In his contribution to this volume, Grégoire Webber objects to splitting up reasoning with rights into the prima facie stage, which is concerned with the question of whether there has been an interference with the right, and the justification stage, where the justification of the interference is examined. ${ }^{31} \mathrm{He}$ believes that invoking the concept of a 'right' for something to which a person has no definite but only an (often quite weak) prima facie entitlement is inappropriate because the prima facie 'right' does not exhibit what for him is a crucial component of the concept of a right, namely its connection with justice. Webber's objection is not to the substance of my theory of rights (it is rather best understood as accusing me of semantic sloppiness), and therefore it is possible to reformulate my approach in a terminology to which Webber would not object. This will enable me to assess whether that terminology is superior to the one which, following an emerging global practice, I have adopted in this contribution as well as in previous work.

We could abandon the language of, for example, 'the right to freedom of expression' and 'the right to life' because, as Webber argues, those 'rights' cannot really be rights, given that they are not absolute: the 'right' to freedom of expression can be limited, for example in the case of hate speech; and the right to life can be limited, for example, in the case of self-defence. Under the approach I advocated above, I can easily fix this assumed problem by distinguishing sharply between the prima facie right and the definite right, and using the term 'right' only for the latter. The definite right that every person has is the right to have his or her autonomy interests adequately taken into account. Thus, Webber would have no objection if instead of a 'right to life' I spoke of a 'right to have one's autonomy interest in life adequately taken into account', or instead of a 'right to freedom of expression' I spoke of a 'right to have one's autonomy interest in freedom of expression adequately taken into account'. Alternatively one could speak, following Kumm, of a 'right to a justification in the case of a limitation of a person's life' / '[...] expression', and so on. Webber would not even object to applying this approach to the right to feed birds or the right to murder: properly understood, we would have to speak of a 'right to have one's autonomy interest in

${ }^{31}$ Grégoire Webber, 'On the Loss of Rights', in this volume; also published at LSE Working Paper Series, No. 16/2013, available online at http://ssrn.com/abstract $=2272978$. 
bird feeding / murder adequately taken into account', or alternatively a 'right to a justification of the prohibition of bird feeding / murder'; and at the level of an accurate use of the concept of a right there is nothing suspicious about this; or in any case, to the extent to which it may still be problematic, it is not Webber's concern in his contribution to this volume.

Thus, achieving the conceptual precision and accuracy Webber insists on is possible, but it comes at a cost: any talk of rights would become semantically awkward and complicated. For example, when designing a new constitution or human rights treaty, or when discussing issues of rights with fellow citizens, we would have to give up including or referring to the 'right to freedom of religion', the 'right to property', and all other commonly acknowledged 'rights', except of course those that even under the global model are absolute (such as the rights to freedom from torture and inhuman and degrading treatment and freedom from slavery). Instead, to avoid the semantic sloppiness that is at the heart of Webber's concern, we could only use the longer and more awkward formulations that I have proposed above.

I am not convinced that this change would be worthwhile. Judges, academics, lawyers, politicians, and ordinary citizens around the world have come to use the phrase 'A has a right to X' (where X could represent, for example, life, freedom of expression, freedom of religion, privacy, property, health care, housing, etc.) in a way that, as I argue, is best reconstructed as invoking not a definite entitlement to $\mathrm{X}$, but rather a prima facie claim that, when interfered with, requires a justification which shows that A's (autonomy) interests in $\mathrm{X}$ have been adequately taken into account. On purely pragmatic grounds, I would object to Webber's proposed change of the usage of the term 'right' because, first, the transactional costs of changing a globally dominant semantic practice would be very high; and, second and more importantly, because I find Webber's alternative, - to replace the language of a 'right to life', a 'right to freedom of expression', etc., with a 'right to have one's interest in life/expression/etc. adequately taken into account'semantically impossibly awkward.

Those pragmatic considerations are sufficient to reject Webber's proposal even on the assumption that he is right in his diagnosis that the world has come to use the word 'right' in a conceptually mistaken way. But there is also reason to doubt the correctness of Webber's diagnosis, because it is based on the misguided assumption that the concept of a right has a meaning which is fixed independently of the particular conception of political morality within which it has a role to play. Thus, he insists that to say that 'A has a right to $\mathrm{X}$ ' necessarily implies that 'it is just that A enjoy $\mathrm{X}$ '. The reason for this, for Webber, is that as a matter of history of ideas, there is an intimate connection between rights and justice. But if for the sake of the argument I grant that this connection is as intimate as Webber claims it is, that still leaves open the possibility that we may have made progress in our understanding of the concept of a right, much in the same way in which we have made or are in the process of making progress with our understanding of other concepts, such as the concept of marriage (as being also available to same-sex 
couples). Under the new, refined understanding of rights, there continues to be a connection between definite rights and justice (although I think this connection is less straightforward than Webber assumes, but that is not the topic here); and there is also a connection between prima facie rights and justice, but it operates in a different way, namely via the duty of justification - which is itself a requirement of justice - that is triggered by an interference with the prima facie right. Therefore, I see no reason to insist that as a matter of semantic or conceptual necessity the phrase 'right to $\mathrm{X}$ ' must refer only to a definite entitlement to $\mathrm{X}$ and cannot possibly refer to an entitlement to have $\mathrm{X}$ adequately taken into account. Of course, whether it is indeed attractive to use the word 'right' in the way that is now globally dominant is a different question and will depend on whether this usage illuminates the structure of the moral-political issues at stake. But this is a substantive question that is not Webber's concern in his contribution to this volume.

Webber has a valid point, though, that followers of what he labels 'the received approach' use the word 'right' sometimes with regard to the prima facie right and sometimes with regard to the definite right. He is certainly right to insist that any usage of the word 'right' should be consistent. But again, I doubt that the stakes are high: once one understands that we have to distinguish between prima facie and definite rights, it is in almost all cases entirely clear which of the two we are referring to; thus, the potential for a good faith misunderstanding is very low. Webber quotes me as arguing that 'proportionality is simply a structure that guides judges through the reasoning process as to whether a policy does or does not respect rights', and takes this as an example of the confusion that may be caused by invoking the concept of a right without making it clear whether one means the prima facie or the definite right. But I doubt that anyone familiar with contemporary human rights discourse would take my statement to mean that proportionality is about determining whether a law interferes with (prima facie) rights; rather, it is obvious that proportionality is a tool used to determine whether a policy violates (definite) rights. The reason I did not specify in the above statement whether it is about prima facie or definite rights is precisely that I considered there to be no potential for misunderstanding. I do not deny the possibility of there being instances in my writing or the writings of other authors where it would have been prudent to add 'prima facie' or 'definite' to the word 'right'; and to the extent that this is so, all of us should pay greater attention to avoid misunderstandings in the future. Furthermore, I accept that ordinary citizens without legal training could occasionally get confused about rights: for example, a would-be bird feeder could respond to the prohibition of bird-feeding in her local park by exclaiming 'But I have a right to feed the birds here!', and a racist could respond to the banning of hate speech by insisting 'But I have a right to freedom of expression!'. Thus, the general point is that people could mistakenly confuse their prima facie rights with their definite rights. But again, while I accept that this is a problem, Webber's alternative, which involves the flat denial of the existence of, for example, a right 
to freedom of expression (because of its lack of absoluteness) would have far more confusing and misleading consequences.

In sum, I do not believe that Webber's strategy of attacking what he calls the received approach and what I have called the global model of constitutional rights on the grounds of its using language in a conceptually inaccurate way is promising: I could, for the sake of the argument, reformulate my approach in a language to which he would not object; but that reformulation would make any discussion of rights semantically impossibly awkward and complicated. As I mentioned in the introduction to this chapter, scholars are only beginning to develop theories of the global model, including its moral defensibility, and a lot of work remains to be done. The most promising engagement with the global model, however, will be one that focuses squarely on its moral attractiveness. Thus, it is of course possible that my argument in this chapter is wrong as a matter of substance, that both rights inflation and proportionality ought to be rejected, and that there exists no general right to have one's autonomy interests adequately taken into account. But those points would have to be argued as a matter of substantive engagement with my or others' theories, not as a matter of the conceptually accurate use of language.

\section{CONCLUSION}

Although the principle of proportionality is widely endorsed in human rights law today, the phenomenon of rights inflation is often viewed with suspicion, as something that ought to be controlled and pushed back rather than embraced. This chapter has argued that the two belong together: we cannot coherently endorse proportionality and reject rights inflation. Rather, endorsing proportionality implies acknowledging a right to feed birds and even a right to murder. But far from concluding that this result shows the absurd consequences of a misguided doctrine, this chapter has defended the conception of constitutional rights that emerges from the endorsement of rights inflation and proportionality: its point is to show a specific kind of respect for persons, which requires that every person's autonomy interests are adequately taken into account at all times. To implement this basic idea in a theory of rights, one must accept, first, a comprehensive (prima facie) right to autonomy whose function it is to ensure that every policy which affects a person's ability to live his life according to his self-conception will interfere with a right and therefore trigger the duty of justification. Second, proportionality analysis must be employed at the justification stage in order to assess whether a policy pays adequate respect to the right-holder's autonomy interests. Thus, rights inflation and proportionality belong together as two building blocks of a globally successful and theoretically attractive conception of rights. 